Revista Brasileira de Informática na Educação - RBIE

Brazilian Journal of Computers in Education

(ISSN online: 2317-6121; print: 1414-5685)

http://br-ie.org/pub/index.php/rbie

\title{
SignWeaver: Plataforma Digital de Apoio à Disseminação de Glossários Bilíngues Libras-Português
}

\author{
Title: SignWeaver: Digital Platform to Support the Dissemination of Libras-Portuguese \\ Bilingual Glossaries
}

Carlos Augusto Guerra Carneiro

Departamento de Computação - CEFET-MG

carlosgcarneyro@gmail.com

Vera Lucia de Souza e Lima

Departamento de Engenharia Civil - CEFET-MG

veralima@civil.cefetmg.br

\author{
Flávio Luis Cardeal Pádua \\ Departamento de Computação - CEFET-MG \\ cardeal@cefetmg.br \\ Celso Luiz de Souza \\ Núcleo de Informática e Gestão - IF Sudeste MG \\ celso.souza@ifsudestemg.edu.br
}

\section{Resumo}

Este trabalho aborda o desenvolvimento de uma plataforma digital, denominada SignWeaver, que apoia a disseminação e manutenção de glossários bilíngues Libras-Português. De forma geral, os vocabulários técnicocientíficos são escassos nos vernáculos das principais línguas de sinais do mundo. Neste contexto, estudantes surdos, intérpretes e professores empenham-se em criar neologismos terminológicos ou sinais-termo em tais áreas, geralmente por meio da organização de comitês locais de discussão, compostos por pessoas da comunidade surda diretamente interessadas. Frequentemente, por meio deste tipo de abordagem, verifica-se que sinais completamente distintos entre si podem ser atribuídos a um mesmo conceito técnico, dificultando-se a comunicação em Libras entre membros de regiões e comunidades diferentes. Neste cenário, a principal contribuição deste trabalho consiste em prover uma plataforma inédita para aglutinar os sinais-termo criados pela comunidade surda e, atualmente, dispersos em diferentes bases de dados pelas diversas regiões do Brasil, facilitando-se a disseminação, adoção e eventual padronização dos sinais-termo em todo o território nacional. Para o desenvolvimento da SignWeaver, utilizaram-se as linguagens PHP e JavaScript, bem como dois arcabouços para desenvolvimento de softwares, quais sejam, o arcabouço Laravel, fundamental para o desenvolvimento dos módulos da plataforma que cuidam da gestão de seus dados (do inglês, back-end side) e o arcabouço Ionic, para o desenvolvimento dos módulos que cuidam das interações com os usuários (do inglês, front-end side). As funcionalidades da SignWeaver foram validadas com sucesso por 65 membros da comunidade surda, em sua maioria, surdos e intérpretes de Libras, sendo que 87,7\% destes prováveis usuários mostraram-se satisfeitos com a plataforma proposta, credenciando-a como uma ferramenta a ser potencialmente utilizada pela comunidade.

Palavras-chave: Língua de Sinais; Libras; Glossários Bilíngues; Plataforma Digital.

\begin{abstract}
This work addresses the development of a digital platform, called SignWeaver, which supports the dissemination and maintenance of bilingual glossaries Libras-Portuguese. In general, technical-scientific vocabularies are scarce in the vernaculars of the major sign languages of the world. In this context, deaf students, interpreters, and teachers strive to create terminological neologisms or term-signs in such areas, usually through the organization of local
\end{abstract}

Cite as: Carneiro, C. A. G., Pádua, F. L. C., Lima, V. L.S \& Souza, C. L. (2019). SignWeaver : Digital Platform to Support the Dissemination of Libras-Portuguese Bilingual Glossaries (SignWeaver: Plataforma Digital de Apoio à Disseminação de Glossários Bilíngues Libras-Português). Brazilian Journal of Computers in Education (Revista Brasileira de Informática na Educação - RBIE), 27(3), 212-241. DOI: 10.5753/RBIE.2019.27.03.212. 
discussion committees, composed of deaf community members directly involved. Often, through this type of approach, it can be seen that completely different signals can be attributed to the same technical concept, making it difficult to communicate in Libras between members of different regions and communities. In this scenario, the main contribution of this work is to provide an original platform for agglutinating the term-signs created by the deaf community and, currently, dispersed in different databases by the different regions of Brazil, facilitating the dissemination, adoption and eventual standardization of the term-signs throughout the national territory. For the development of SignWeaver, the PHP and JavaScript languages were used, as well as two frameworks for software development, namely the Laravel framework, which is fundamental for the development of the modules of the platform that manages the data (back-end side) and the Ionic framework for developing front-end side modules. SignWeaver 's features were successfully validated by 65 members of the deaf community, mostly deaf and Libras interpreters, and $87.7 \%$ of these potential users were satisfied with the proposed platform, accrediting it as a tool to be potentially used by the deaf community.

Keywords: Sign language; Libras; Bilingual glossaries; Digital platform. 


\section{Introdução}

Aproximadamente 5\% da população mundial, cerca de 360 milhões de pessoas, têm perda auditiva incapacitante, sendo que a maioria dessas pessoas vivem em países de baixa e média renda (OMS, 2017). No Brasil, são aproximadamente 9,7 milhões de pessoas com deficiência auditiva, ou seja, observa-se o mesmo percentual mundial (cerca de $5 \%$ da população), sendo quase um milhão de jovens com idade até 19 anos (IBGE, 2010).

Nos países em desenvolvimento, muitas crianças com perda auditiva e surdez não têm acesso ao ensino e os adultos surdos não conseguem se inserir no mundo do trabalho, quando muito, ocupam cargos operacionais e, em geral, que exigem pouca ou nenhuma qualificação. Para reduzir estas taxas de desemprego, deve-se melhorar o acesso à educação e a serviços de reabilitação vocacional, além de conscientizar o mercado de trabalho sobre as necessidades de contratar estas pessoas (OMS, 2017).

Apesar dos grandes avanços alcançados, os surdos ainda possuem grandes dificuldades quando ingressam no meio acadêmico. Existe uma grande escassez de termos em Libras nas mais diversas áreas do ensino, prejudicando o aprendizado do estudante surdo (Lima, 2014). Os principais dicionários da língua portuguesa têm em torno de 200 mil palavras, já o principal dicionário da Libras (Capovilla, Raphael, e Mauricio, 2008) tem menos de 10 mil sinais. Estes números são para a língua geral, sendo que para as áreas de Ciências, Tecnologia, Engenharia e Matemática (CTEM), os sinais em Libras, apesar de existirem alguns, não têm sido devidamente registrados em dicionários (Lima, 2014).

De fato, verifica-se que os vocabulários técnicos não são encontrados nos vernáculos das principais línguas de sinais do mundo (Lima, 2014). Neste contexto, intérpretes, professores e tutores, esforçam-se para criar sinais-termo em tais áreas, frequentemente por meio da organização de comitês locais de discussão, compostos por pessoas da comunidade surda diretamente interessadas. Os produtos resultantes desses esforços incluem não apenas dicionários, mas também coleções de sinais que podem estar, por exemplo, sob a forma impressa ou em diferentes formatos de mídias digitais (Holgate, 2015; Marschark e Spencer, 2010). Frequentemente, por meio deste tipo de abordagem, verifica-se que sinais completamente distintos entre si podem ser atribuídos a um mesmo conceito técnico, quando intérpretes ou instituições de ensino diferentes realizam este trabalho de forma independente.

Comumente, nas mais diversas áreas e níveis do ensino, a criação de sinais acontece na sala de aula durante a interação entre o surdo e o intérprete após perceberem que não existem sinais para os conceitos abordados pelo professor. Apesar disto ser um procedimento comum, estes termos não são dicionarizados e acabam se perdendo quando um intérprete ou o aluno mudam de escola. Além disto, estes sinais não são de conhecimento de todos e, por isso, não são intercambiados entre instituições ou até mesmo entre as salas de aula de uma mesma instituição (Lima, 2014; Souza, de Lima, e Pádua, 2014).

Portanto, nota-se que o problema da escassez de um léxico específico para termos técnicos 
em línguas de sinais é algo crítico e de difícil solução, sobretudo quando se considera que os vocabulários técnicos trazem consigo desafios diferentes daqueles observados em situações de leitura comuns, não apenas para pessoas com perda auditiva, mas para todos os alunos (Bigham, Otero, DeWitt, Cavender, e Ladner, 2008). Ademais, deve-se ressaltar que a maioria dos indivíduos surdos ou com algum grau severo de deficiência auditiva possuem dificuldade em compreender a língua oral do país em que vivem. Ou seja, tais indivíduos são fortemente dependentes da interpretação da língua de sinais que utilizam para compreender o que está escrito (Souza et al., 2014).

Neste contexto, buscando-se contribuir para a solução do problema de ausência de terminologia em Libras para conceitos técnico-científicos e consequentemente auxiliar o surdo a ingressar no mundo acadêmico e no mercado de trabalho qualificado, este trabalho aborda o desenvolvimento da plataforma SignWeaver, a qual visa apoiar a criação, disseminação e manutenção de glossários bilíngues Libras-Português. Por meio da plataforma SignWeaver, poderão ser disponibilizados em uma única base de dados, acessível por meio da Web e dispositivos móveis, os principais sinais-termo já criados pela comunidade surda brasileira. Portanto, esta plataforma poderá apoiar de forma inédita o trabalho de aglutinação de tais sinais, atualmente, dispersos em diferentes bases de dados pelas diversas regiões do Brasil. Adicionalmente, por meio da SignWeaver poderão ser criados sinais-termo em Libras, de forma parametrizada, ágil e escalável, para conceitos que eventualmente ainda não tenham sinais previamente criados, mais especificamente por meio da utilização da abordagem proposta por Souza, Pádua, Lima, Lacerda, e Carneiro (2018), que fundamenta o funcionamento de um dos módulos da plataforma SignWeaver.

Nessa seção foi apresentada uma contextualização geral, além de descrever o principal objetivo que este trabalho pretendeu alcançar. A Seção 2 descreve os conceitos fundamentais para o desenvolvimento deste trabalho. Os trabalhos que inspiraram ou que de alguma forma se relacionam com o trabalho desenvolvido são mostrados na Seção 3. O desenvolvimento da plataforma é apresentado na Seção 4, onde são descritas as principais tarefas desenvolvidas para alcançar os objetivos traçados. Na Seção 5 é descrito o processo de avaliação da plataforma por representantes da comunidade surda. Por fim, na Seção 6 são apresentadas as conclusões obtidas, bem como as propostas de trabalhos futuros a serem desenvolvidas.

\section{Fundamentação Teórica}

Este capítulo descreve os principais conceitos e métodos relacionados ao trabalho desenvolvido. Na Subseção 2.1 será feita uma explicação das línguas de sinais, mostrando algumas de suas características. Já na Subseção 2.2 será mostrado o impacto da tecnologia na educação da comunidade surda. 


\subsection{Línguas de Sinais}

Assim como as línguas orais, as línguas de sinais possuem as nove características linguísticas propostas por Hockett (1960), sendo elas o modo de comunicação, semanticidade, função pragmática, permutabilidade, transmissão cultural, arbitrariedade, diferenciação, deslocamento e produtividade. Possuem gramática própria e podem ser utilizadas, inclusive, para discutir assuntos complexos e abstratos.

As línguas de sinais se diferem entre países e são independentes da língua oral adotada em um país, como por exemplo a Língua Brasileira de Sinais (Libras) no Brasil, Língua Gestual Portuguesa (LGP) em Portugal, Língua Britânica de Sinais (BSL) no Reino Unido, Língua Americana de Sinais (ASL) nos Estados Unidos, Língua de Sinais Irlandesa (ISL) na Irlanda. Elas não, necessariamente, têm relação visual com seu referente, assim como línguas orais não são onomatopaicas ${ }^{1}$, portanto não são meramente mímicas (Johnston, 1989; Stumpf, 2005).

Muitas vezes, quando não existe o sinal para um conceito técnico ou para nomes próprios, realiza-se a datilologia da palavra escrita em uma língua oral. Para exemplificar, a Figura 1 mostra o sinal e, posteriormente, a datilologia da palavra CASA em Libras. O uso da datilologia em alguns casos pode ser fonte de novos sinais, chamados de sinais lexicalizados (Nakamura, 1995).
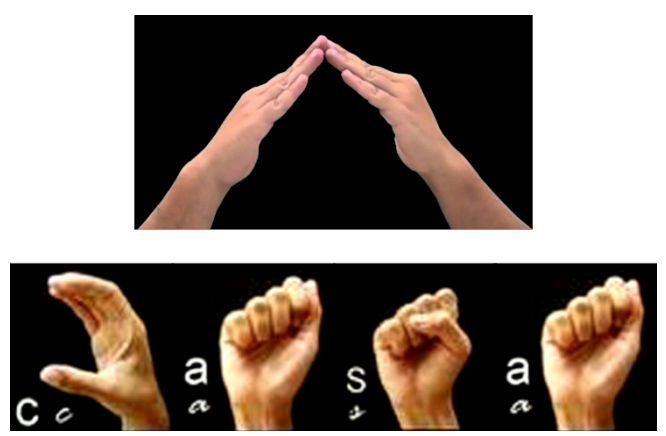

Figura 1: Sinal e datilologia da palavra CASA em Libras

\subsubsection{Lingua Brasileira de Sinais}

Em 1855 chegou ao Brasil, a convite de D. Pedro II, o francês Eduardo Huet para começar a trabalhar a educação dos surdos. Então, em 26 de setembro de 1857, foi criado na cidade do Rio de Janeiro o Imperial Instituto de Surdos Mudos, atualmente chamado de Instituto Nacional de Educação de Surdos (INES). Vários dos sinais que são utilizados hoje pelas comunidades surdas brasileiras foram criados por um ex-aluno do Instituto, Flausino José da Gama, que criou, em 1875, um pequeno vocabulário ilustrado de sinais brasileiros chamado Iconografia dos Signaes dos Surdos-Mudos (Lima, 2014).

\footnotetext{
${ }^{1}$ Onomatopeia: figura de linguagem que reproduz um som com um fonema ou palavra.
} 
Em 24 de abril de 2002 a Língua Brasileira de Sinais foi reconhecida oficialmente pela Lei Federal n o 10.436 (Brasil, 2002), regulamentada pelo Decreto Lei n o 5.626 de 22 de dezembro de 2005 (Brasil, 2005). Cabe ressaltar que, anteriormente ao reconhecimento nacional, em 10 de janeiro de 1991, o Estado de Minas Gerais reconheceu a Libras por meio da Lei n o 10.379. Agora é assegurado aos surdos o direito de serem educados em sua própria língua e serem auxiliados por intérpretes em espaços públicos, educacionais e em meios de comunicações.

\subsubsection{Escrita de sinais}

A cultura surda está pouco registrada, porque por muito tempo não existiu uma forma de escrita de sinais. A transcrição de fatos narrados por surdos era feita por meio da forma escrita das línguas orais do país em que viviam (Stumpf, 2005).

Um dos primeiros sistemas de escritas foi proposto por Stokoe (1960), criando um sistema baseado no alfabeto latino para descrever a Língua de Sinais Americana (ASL). Desde Stokoe vários outros autores propuseram novos sistemas de escrita, sendo os um dos mais conhecidos o sistema Hamburg Notation System (HamNoSys) (Prillwitz, 1989) e o SignWriting (Sutton, 1995).

Por ser um sistema de escrita amplamente reconhecido, no que diz respeito à transcrição de línguas de sinais, no mundo, e mais especificamente no Brasil, o sistema SignWriting é utilizado nesse trabalho para transcrever os sinais armazenados na plataforma desenvolvida.

\subsubsection{Glossários em Línguas de Sinais}

A Libras não possui, formalmente ou oficialmente, um glossário ou mesmo um marco teórico para a produção de obras Lexicográficas Terminológicas. Algumas pesquisas já mostraram a necessidade de se criar terminologia em Libras para conceitos técnicos e que também existem pesquisas que propuseram a criação de sinais para estes conceitos.

Um exemplo de trabalho que propõe a criação de terminologia em Libras é o trabalho de Carmona et al. (2015), em que foi feito um levantamento de quais termos são utilizados no ensino de biologia e, a partir disso, foi feita uma pesquisa nos principais dicionários, de Libras e de outras línguas de sinais, para verificar se existiam sinais para os conceitos abordados em biologia. Foi constatado que sinais para essa área são praticamente inexistentes, e devido a este fato, formou-se uma equipe multidisciplinar auxiliar alunos surdos do ensino médio na elaboração de um glossário para biologia em Libras. Como resultado do trabalho foram criados 367 sinais para os conceitos selecionados.

\subsection{Educação de Surdos e Novas Tecnologias}

A chegada do computador e da Internet inaugurou uma nova era para a comunicação dos surdos, pois são tecnologias com suporte visual e a comunicação por meio das mesmas pode ser feita por meio de textos, imagens e vídeos. O meio digital revolucionou a vida dos ouvintes, mas para os 
surdos esta mudança foi ainda maior.

Os alunos que são surdos ou com deficiência auditiva necessitam que todas as informações faladas ou sonoras em sala de aula sejam apresentadas visualmente. Isso geralmente é realizado por meio de intérpretes de língua de sinais ou transcritores em tempo real. Além disso, as formas visuais alternativas de exibir informações podem beneficiar estudantes surdos e com deficiência auditiva e tornar os conceitos-chave mais claros (Cavender e Ladner, 2010).

Professores e gestores ainda não estão preparados para lidar com essa forma de comunicação, o que dificulta o aprendizado de conteúdos importantes por alunos surdos, inclusive a própria língua. Para solucionar este problema, alguns trabalhos propuseram o desenvolvimento de ferramentas tecnológicas para facilitar a comunicação entre pessoas com diferentes tipos de deficiência, inclusive os surdos (P. S. R. Rocha, Lima, e Queiroz, 2018).

Cada vez mais é crescente o número de trabalhos que propõem tecnologias para serem utilizadas no ensino de estudantes surdos. Quando somente a língua oral é utilizada, indivíduos surdos ou com alguma dificuldade em escutar não participam integralmente do processo de ensino. A tecnologia educacional oferece aos alunos e professores um método de apresentação de informações visuais e interativas, permitindo a troca de ideias e pensamentos com todos os alunos. A tecnologia educacional, oferecendo métodos visuais de apresentação de informação aos alunos (como os trabalhos de Kushalnagar, Cavender, e Pâris (2010) e Drigas, Vrettaros, Stavrou, e Kouremenos (2004)) e modos efetivos de comunicação, permite que alunos, com qualquer grau de surdez, não terem dificuldades no processo de aprendizado (Roberson, 2001).

\section{Trabalhos Relacionados}

Trabalhos recentes abordaram o problema do desenvolvimento de sinais para conceitos técnicos por meio de uma análise cuidadosa por comitês de especialistas ou mesmo trabalhos colaborativos que envolvem diferentes pessoas da comunidade surda, resultando em dicionários de línguas de sinais disponibilizados on-line ou, por exemplo, em outras mídias, como DVD (Bigham et al., 2008; Carmona et al., 2015; Cavender e Ladner, 2010; Holgate, 2015).

Como Libras é a língua de sinal utilizada neste trabalho para demonstrar a aplicabilidade da abordagem proposta nesse trabalho, no que diz respeito ao desenvolvimento de glossários em Libras, é importante mencionar as contribuições de Nascimento et al. (2011), Felipe (2006) e Lima (2014). Estes trabalhos propõem um conjunto de premissas para o desenvolvimento de dicionários em línguas de sinais, baseados em lexicografia e seus sistemas de representação.

Em Nascimento et al. (2011), são explicados os aspectos léxicos e terminológicos da Libras, ressaltando as características estruturais principais para o desenvolvimento de um glossário bilíngue. Felipe (2006) investiga a expansão lexical e terminológica na Libras, assim como os processos que denominam categorias e constroem classificadores da Libras para organizar as entradas do seu repertório lexicográfico. Lima (2014) desenvolveu procedimentos metodológicos 
para a criação de um glossário bilíngue, ilustrado e bimodal (Língua Portuguesa e Libras), fundamentado em um corpus de termos da área de Desenho Arquitetônico.

Neste caminho, um outro exemplo de trabalho que propôs a criação de terminologia é o trabalho de Barral, Da Silva, e Rumjanek (2017). Neste trabalho foi proposta uma metodologia para a produção de um Glossário Científico em Libras, onde foram desenvolvidos quatro fascículos temáticos na área biológica, somando um total de 426 sinais, dos quais apenas 74 já existiam em Libras. Os sinais foram avaliados por surdos do Rio de Janeiro e da Paraíba, sendo que 352 foram validados por estes surdos. $\mathrm{O}$ trabalho ainda segue em desenvolvimento, mas com a possibilidade de empréstimos linguísticos de outras línguas de sinais.

Existem também trabalhos que propuseram facilitar a divulgação de sinais já existentes, como por exemplo o trabalho de D. F. S. Rocha, Pinto, e Silva (2015) onde foi desenvolvida uma ferramenta, denominada AssistLIBRAS, que permite ao usuário gerar a sinalização de conceitos em Libras, por meio de um avatar, sem a necessidade de ter conhecimentos técnicos na área de computação. Apesar da proposta ser promissora, o trabalho foi uma abordagem conceitual e não foi devidamente avaliada por membros da comunidade surda. Já no trabalho de Travassos Sarinho (2017), foi desenvolvido um jogo no estilo Quiz que funciona nos aplicativos WhatsApp, Messenger e Telegram onde os conhecimentos, em Libras, do usuário são testados por meio de arquivos de vídeo.

Em todo o mundo existem propostas para a criação, validação, preservação e divulgação de terminologia em línguas de sinais. Mas, nas pesquisas realizadas, não foi encontrada uma proposta que tenha como objetivo de ser uma única plataforma onde tudo isso irá acontecer. Espera-se com esse trabalho, incentivar a produção de terminologia em línguas de sinais, além de facilitar o acesso da comunidade surda a essas terminologias.

\section{Plataforma Digital}

Esta seção descreve o desenvolvimento da plataforma digital proposta para a criação, validação e preservação de glossários em Libras. Como estudo de caso inicial, têm-se como meta, a inserção de glossários que possuem conceitos utilizados nas principais disciplinas que compõem o Ensino Médio (e. g. Matemática, Português, Física, História, entre outras).

\subsection{Requisitos}

O passo inicial para o desenvolvimento da plataforma foi o levantamento de requisitos. Nesta etapa foram definidos os módulos que fazem parte da plataforma e as tecnologias utilizadas. Para a realização desta etapa, foi utilizado como referência o trabalho de Lima (2014).

O trabalho de Lima (2014) foi utilizado como base para a descrição dos requisitos necessários para o "Módulo de Interação com o Usuário" (Subsubseção 4.3.2) e o "Módulo de 
Avaliação de Sinais" (Subsubseção 4.3.3). Lima (2014) define 3 conceitos importantes para a formação desses 2 módulos:

- Ficha Lexicográfica: A ficha lexicográfica, Figura 2, descreve foneticamente um sinal. Ela mostra informações específicas de um conceito atendendo às especificidades do registro em Libras;

- Verbete: O verbete é considerado a unidade mínima na organização de um glossário. Ele apresenta informações sistemáticas e não sistemáticas, sendo as sistemáticas: entrada em português; classe morfológica, seguida do gênero; definição. Os verbetes podem estar ordenados por ordem alfabética, configurações de mãos ou pelo percurso onomasiológico ${ }^{2}$;

- Comitê Validador: Lima (2014) criou dentro dos pré-requisitos da sua pesquisa um comitê validador composto por surdos, intérpretes, especialista na área à qual o glossário faz parte e especialista em linguística.

Em seu trabalho, como estudo de caso, Lima (2014) criou sinais que representam conceitos da disciplina de Desenho Arquitetônico. Lima (2014) definiu a forma que um verbete deve ser apresentado caso o mesmo faça parte de um glossário impresso.

Com base no que foi apresentado acima, os requisitos do sistema, são descritos a seguir.

\subsubsection{Módulos do Sistema}

Nesta etapa de levantamento de requisitos, a plataforma desenvolvida foi dividida em 5 módulos, sendo eles o Módulo de Acesso à Plataforma (módulo 1), Módulo de Interação com o Usuário (módulo 2), Módulo de Avaliação de Sinais (módulo 3), Módulo de Geração de Sinais (módulo 4) e Módulo de Sinalização (módulo 5).

Inicialmente o módulo 4 deveria ser responsável por propor sinais-termo que iriam compor os glossários a serem armazenados nesta plataforma, mas, foi identificado que existe uma demanda por uma plataforma que possa disponibilizar terminologia criada por pesquisadores de diversas áreas. Sendo assim, foi definido que essa plataforma digital deveria armazenar sinais-termo desenvolvidos por trabalhos que criaram terminologia em línguas de sinais ou propostos por um comitê avaliador. Apesar de terem sido desenvolvidas, nesse trabalho, funcionalidades que integram o gerador de sinais-termo, proposto por Souza, de Lima, e Pádua (2018), à plataforma SignWeaver, a incorporação do gerador à plataforma e a utilização do mesmo será feita em trabalhos futuros. Foi definido também que antes de disponibilizar sinais-termo à plataforma SignWeaver, os mesmos serão avaliados por um comitê avaliador.

Para uma melhor compreensão, a Figura 3 exibe uma visão geral do funcionamento da plataforma desenvolvida.

\footnotetext{
${ }^{2} \mathrm{~A}$ ordenação onomasiológica tem como ponto de partida os significados dos termos.
} 


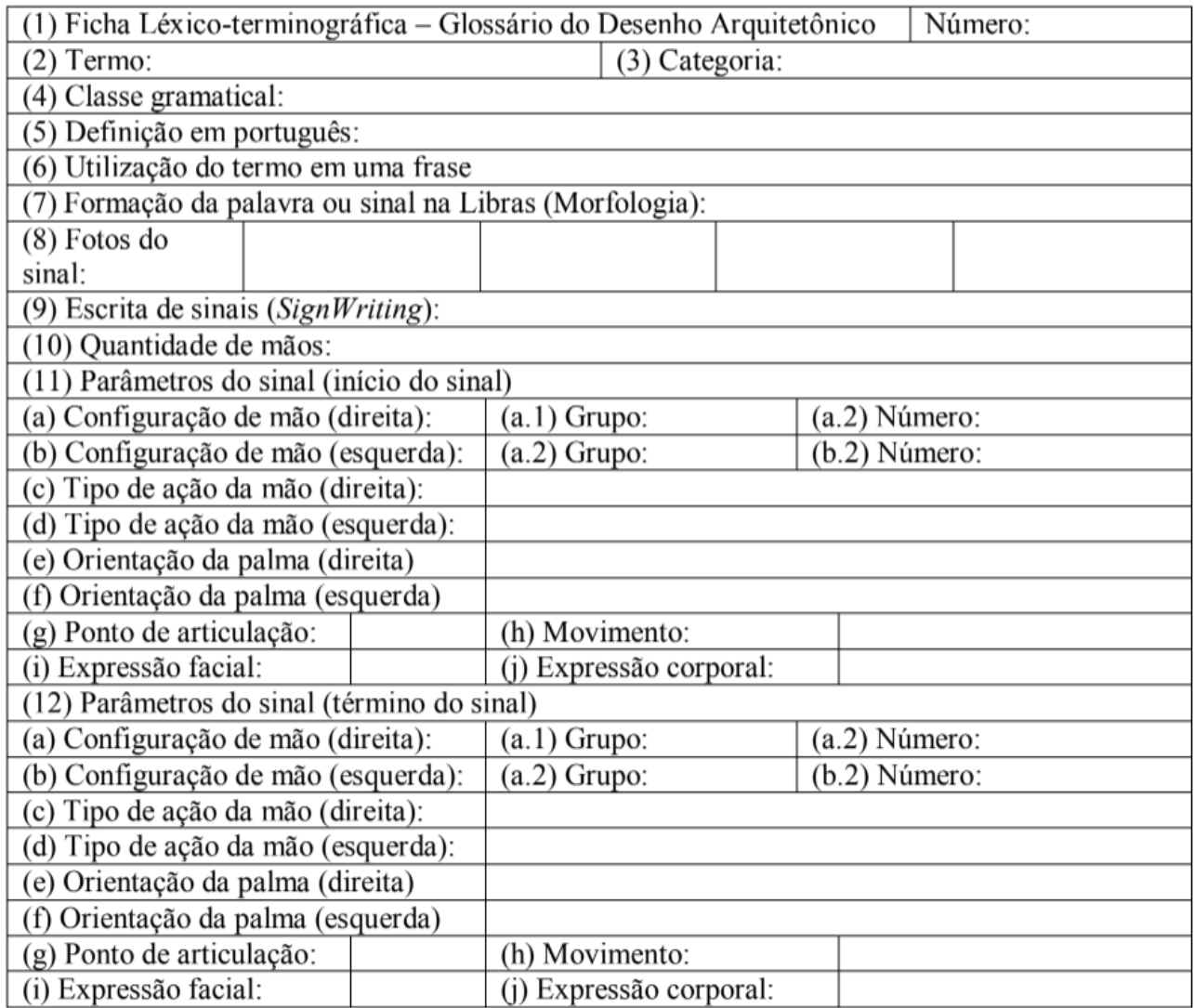

Figura 2: Modelo de ficha lexicográfica.

Os cinco módulos principais da plataforma são brevemente descritos a seguir:

1. Módulo de Acesso à Plataforma: Este módulo é responsável pelo cadastro de usuários, além de ser responsável por controlar o acesso às funcionalidades da plataforma;

2. Módulo de Interação com o Usuário: É este módulo que é de interesse do público, ele deve exibir todos os sinais criados, e já validados anteriormente, além de exibir a informação dos termos buscados;

3. Módulo de Avaliação de Sinais: Este módulo é utilizado exclusivamente por membros do comitê avaliador de sinais criados ou incorporados à plataforma. É neste módulo que um sinal proposto pelo Módulo de Geração de Sinais é validado e, caso necessário, é neste módulo onde o comitê propõe um novo sinal;

4. Módulo de Geração de Sinais: Este módulo é responsável por propor um novo sinal para um determinado conceito técnico. Ele tem como resultado o sinal codificado em SignWriting; 


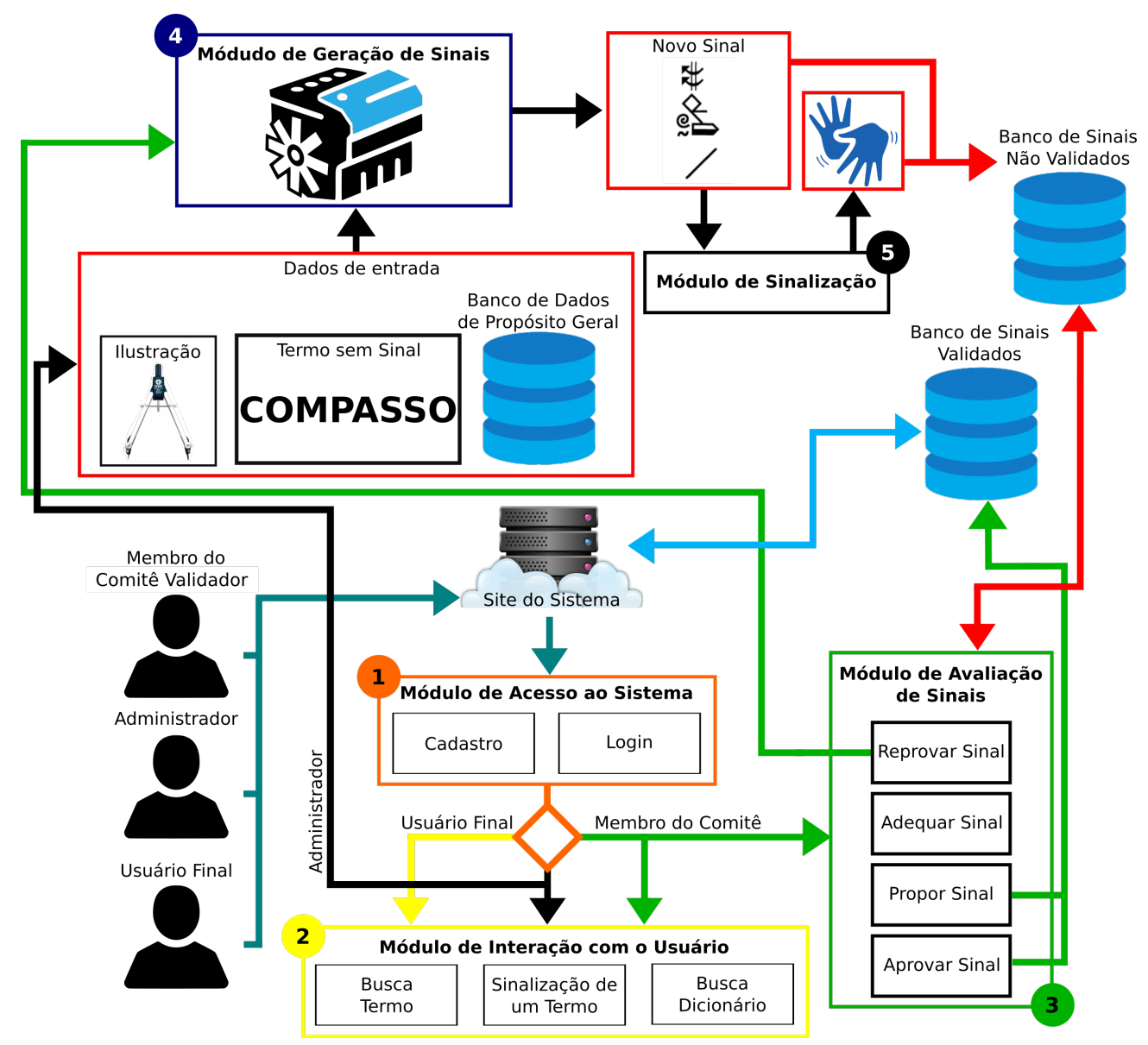

Figura 3: Diagrama que descreve o funcionamento da plataforma digital..

5. Módulo de Sinalização: Após ser criado, um sinal-termo e sua definição devem ser filmados e armazenados por meio deste módulo.

\subsubsection{Usuários}

Como pode ser visto na Figura 3, as funções dos usuários no sistema também foram definidas. A Figura 4 apresenta um diagrama UML que sintetiza as principais funções e atores envolvidos na plataforma digital. Nota-se, a partir da Figura 3 e Figura 4, que há três tipos de usuários básicos, caracterizados como "Membro do Comitê Avaliador", "Administrador" ou "Usuário Final".

Um "Membro do Comitê Validador" deverá acessar a plataforma e avaliar os sinais não validados, mas já armazenados na plataforma, podendo aprovar, adequar, propor ou reprovar um sinal. Um sinal-termo será armazenado no banco de sinais já validados caso comitê avaliador aprove, adéque ou proponha um novo sinal. Caso o sinal seja reprovado pelo comitê avaliador, em trabalhos futuros, será solicitado ao módulo 4 que gere um novo sinal, sendo necessária uma nova 
avaliação do comitê.

O usuário "Administrador" é responsável por inserir os dados de entrada necessários para o funcionamento do módulo 4. Os dados inseridos, pelo administrador, são: a ilustração que representa o conceito técnico sem sinal e o seu termo correspondente em língua oral, neste caso em português. Quando os dados necessários para o funcionamento do gerador de sinais já estiverem armazenados na plataforma, o administrador pode solicitar a geração de sinais para as entradas armazenadas por ele.

Por outro lado, o usuário chamado "Usuário Final" (e.g.: surdos, intérpretes ou pessoas que estão estudando Libras), ao consultar um termo pertencente a um dicionário já validado, utiliza o módulo 2, para que possa visualizar a definição e a sinalização do conceito. Estas ações também podem ser executadas pelos usuários do tipo "Membro do Comitê Avaliador" e "Administrador".

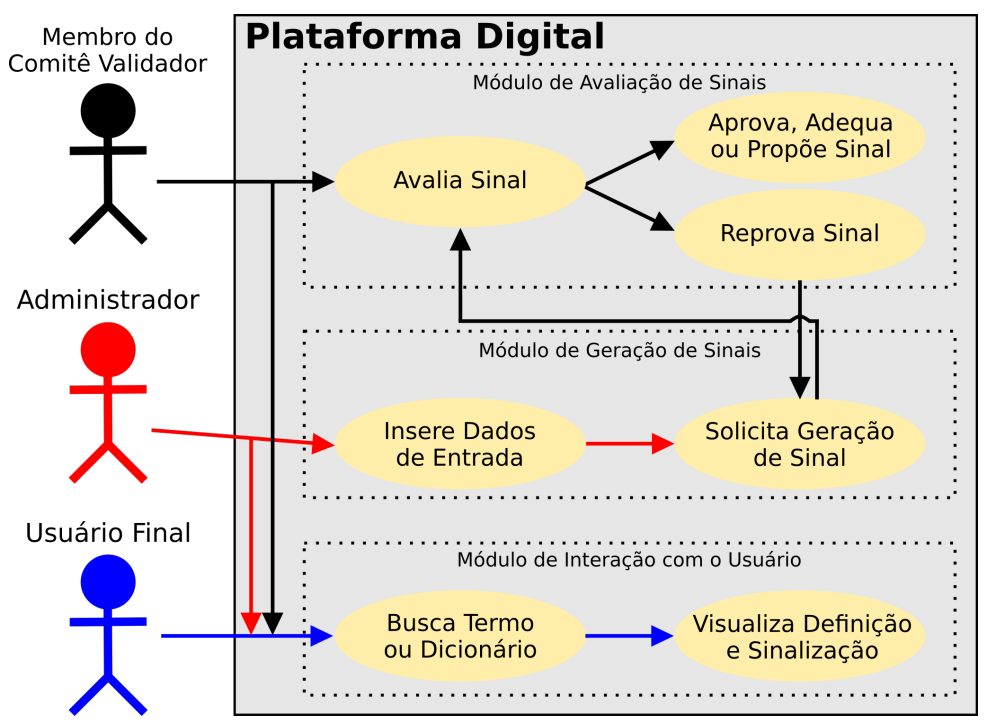

Figura 4: Diagrama que descreve o funcionamento da plataforma digital.

\subsubsection{Tecnologias Utilizadas}

Foi definido, também nesta etapa, que a plataforma digital deveria ser utilizada tanto por meio de uma página na Internet, como por meio de um aplicativo para dispositivos móveis. Os arcabouços tecnológicos escolhidos para o desenvolvimento da plataforma foram o Laravel e o Ionic. A escolha destes dois arcabouços veio da necessidade de reduzir a quantidade de código desenvolvido, sendo que a utilização do Ionic permitiu que a plataforma esteja disponível para vários sistemas operacionais (iOS, Android, Windows, Linux, etc.) sem ter que desenvolver um código para cada tipo de sistema operacional. Já Laravel ficou responsável por receber as solicitações dos usuários e processá-las no servidor.

O diagrama relacional do banco de dados não foi totalmente projetado nesta etapa, pois ele 
foi sendo criado de acordo com o desenvolvimento da plataforma. Isto se deve ao fato do Laravel ir criando as tabelas no banco de dados de acordo com o desenvolvimento das classes que as representam. Esta facilidade se deve ao fato do Laravel utilizar o MOR (Mapeamento ObjetoRelacional) Eloquent. O Eloquent, faz com que a interação com o banco de dados se torne mais fácil e elegante, transformando uma tabela do banco de dados em uma classe do PHP. Apesar disto, os relacionamentos previamente estabelecidos foram definidos de acordo com a Figura 5. O sistema de gerenciamento de banco de dados (SGBD) utilizado foi o MySql.

A utilização do Laravel e do Ionic, permite a criação de uma aplicação RESTful ${ }^{3}$. Todas as interações entre a aplicação cliente e o servidor seguiram a arquitetura REST.

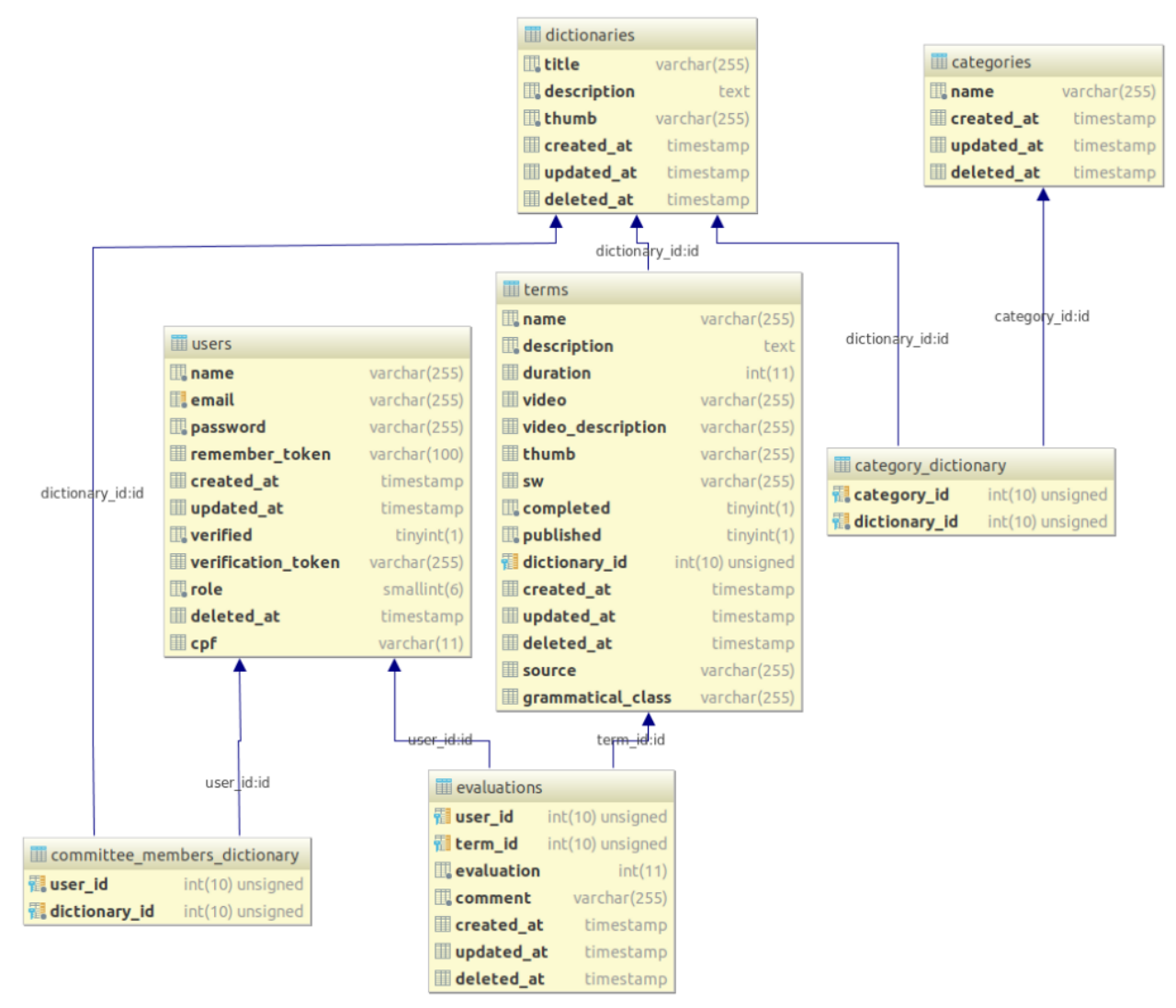

Figura 5: Diagrama Relacional que descreve as classes principais do sistema e as suas relações.

\subsection{Análise dos requisitos}

A partir da definição dos módulos do sistema, das tecnologias a serem utilizadas e das funções dos usuários, foi possível levantar os seguintes requisitos funcionais:

\footnotetext{
${ }^{3}$ Aplicação que utiliza REST, ou seja, qualquer aplicação que utiliza JSON (ou XML) e HTTP, sem as abstrações adicionais dos protocolos baseados em padrões de trocas de mensagem.
} 
1. Possuir tela para o cadastro de atividades;

- Este requisito é importante para que a plataforma consiga distinguir os diferentes tipos de usuários que a utilizarão.

2. Armazenar textos e arquivos de vídeo e imagem;

- A microestrutura de um verbete deve ser composta por: entrada em português; classe morfológica, sinal e definição em uma língua de sinal, definição na língua oral correspondente, autor do sinal-termo, ilustração que representa o conceito abordado e o SignWriting que representa o sinal termo.

3. Possuir tela de cadastro, edição e deleção de glossários e seus respectivos verbetes;

4. Possuir tela de cadastro, edição e deleção de usuários da plataforma;

- É nesta tela que um usuário do tipo "Administrador" pode cadastrar, editar (inclusive alterando o tipo do usuário) e excluir usuários.

5. Possuir interface para visualização dos glossários e seus respectivos sinais-termo cadastrados;

6. Possuir interface para avaliação dos sinais-termo não validados;

7. Possibilitar a visualização dos vídeos, dos sinais-termo e definição de em língua de sinal, adaptável de acordo com a velocidade de conexão do usuário;

8. Fornecer área de busca para os conceitos já validados e armazenados na plataforma;

9. Possibilitar ao usuário do tipo "Administrador" a visualização dos dados armazenados na plataforma;

10. Possuir interface para que os usuários do tipo "Membro do Comitê Validador" possam validar, alterar ou reprovar um sinal-termo para um determinado conceito;

11. Possuir interface para que os usuários do tipo "Membro do Comitê Validador" e "Usuário Final" possam alterar a senha de acesso à plataforma.

Além dos requisitos funcionais, os requisitos não-funcionais foram definidos como:

1. A plataforma SignWeaver deve ser executada em vários sistemas operacionais;

2. A SignWeaver deve ser acessível via internet;

3. A SignWeaver deve suportar uma grande quantidade de dados;

4. A plataforma deve ser de uso gratuito.

Levantados o requisitos funcionais e não funcionais, o processo de desenvolvimento pôde ser iniciado. Esse processo é explicado na Subseção 4.3. 


\subsection{Desenvolvimento da plataforma}

Logo após o levantamento dos requisitos, foi iniciada a etapa de desenvolvimento da plataforma. Nesta etapa foram aperfeiçoados os conhecimentos sobre as tecnologias utilizadas e paralelamente foi feita a codificação. O desenvolvimento de cada módulo da plataforma é melhor descrito na Subsubseção 4.3.1, Subsubseção 4.3.2, Subsubseção 4.3.3, Subsubseção 4.3.4 e Subsubseção 4.3.5.

\subsubsection{Módulo de Acesso à Plataforma}

O Módulo de Acesso à Plataforma é responsável por cadastrar usuários e controlar o acesso aos módulos da plataforma de acordo com o tipo de usuário. A sua interface com os usuários nada mais é do que uma tela de login, uma tela de cadastro e uma tela de alteração de senha.

A tela de login, Figura 6, foi pensada para ser a mais simples possível, para que o usuário não tenha dúvidas do que fazer. Além disto, consta a opção para cadastro na plataforma. A Figura 7 exibe a tela de cadastro de usuários.

Ao realizar o cadastro na plataforma, um novo registro é armazenado na tabela "users" de acordo com os dados passados pelo usuário. Ao realizar o cadastro, o usuário deve verificar a caixa e-mail do endereço informado, pois receberá uma mensagem para que valide o endereço de e-mail cadastrado. De forma padrão, os campos "role" e "verified" são definidos como 1 e 0 respectivamente, sendo o atributo "role" tendo o valor definido como 1 pelo fato de todo usuário cadastrado na plataforma, por padrão, ser do tipo "Usuário Final" e o atributo "verified" tendo o valor definido como 0 pelo fato de todo usuário cadastrado na plataforma, por padrão, ter o estado de não verificado. O atributo "verified" é alterado, para 1, quando o usuário confirma o e-mail recebido.
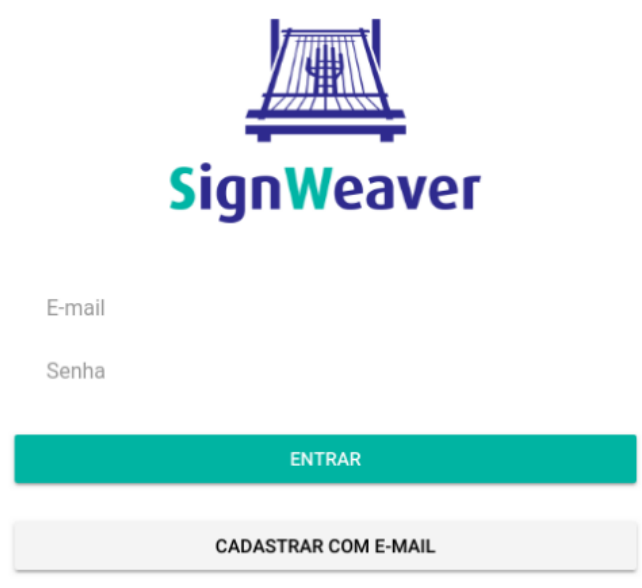

Figura 6: Tela de login. 


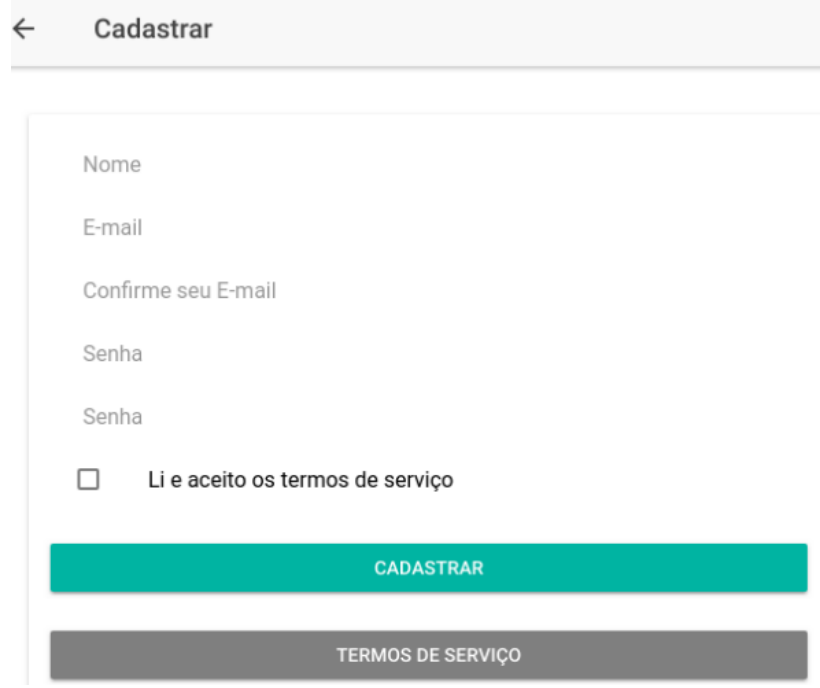

Figura 7: Tela de cadastro.

\subsubsection{Módulo de Interação com o Usuário}

Após ser reconhecido ao fazer login, o usuário é redirecionado para a página que contém os glossários contidos na plataforma. A Figura 8 exibe a interface onde os usuários visualizam os glossários da plataforma.

Após selecionar um glossário, o usuário é redirecionado para a tela onde contém os verbetes pertencentes ao glossário selecionado. A Figura 9 exibe os verbetes do glossário de "Sangue" e a Figura 10 exibe a definição do verbete "Alvéolo Pulmonar".

\section{$\equiv$ Glossários}

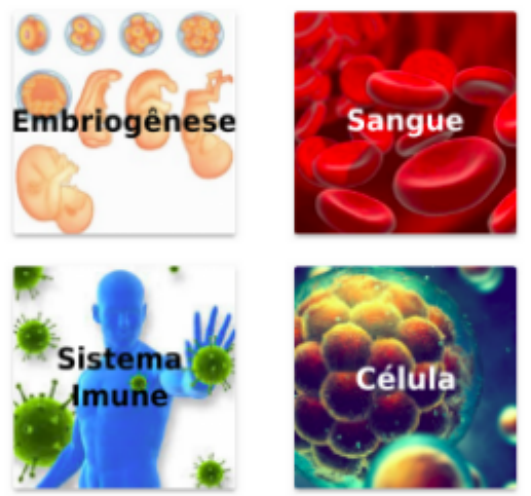

Figura 8: Tela que exibe os glossários cadastrados na plataforma. 


\section{$\leftarrow \quad$ Sinais-termo

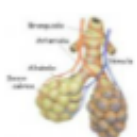

\section{Alvéolo Pulmonar}

Os alvéolos pulmonares são estrutura.

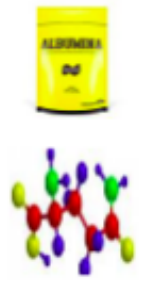

\section{Albumina}

Albumina (latim: albus, branco) refere-.

\section{Aminoácido}

Aminoácidos são substâncias orgânic..

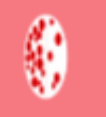

Anemia

Condiçẵo em que o sangue não tem u.

Figura 9: Tela que exibe os verbetes pertencentes ao glossário de "Sangue".

\section{$\leftarrow \quad$ Sangue > Alvéolo Pulmonar}

Vídeo do Sinal-Termo

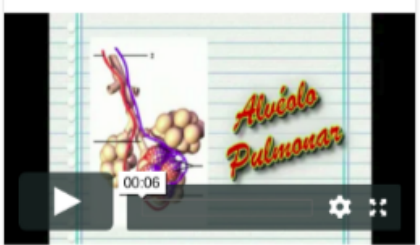

\section{Alvéolo Pulmonar}

Substantivo Masculino

Os alvéolos pulmonares săo estruturas de pequenas dimensठ̌es às quais eståo se realiza a troca gasosa.

Fonte: Instituto de Bioquimica Médica , UFRJ

Áreas do Conhecimento: Biologia Geral

Vídeo da Definiçăo

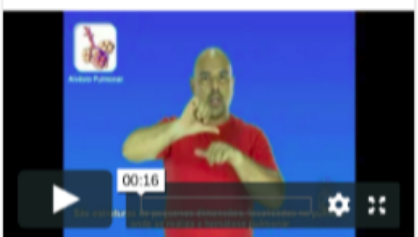

$$
\text { SingWriting }
$$
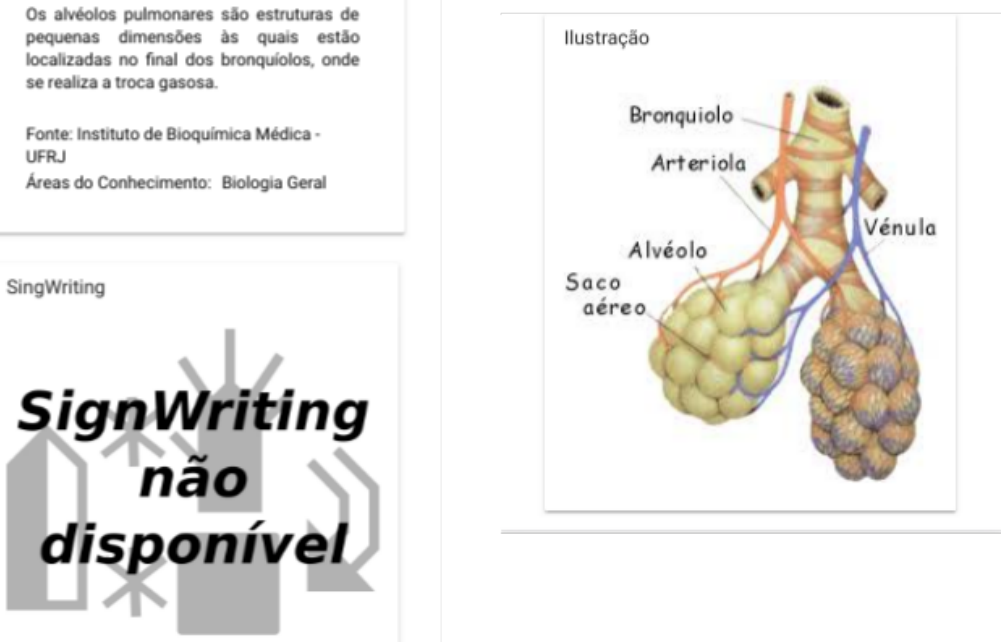

Figura 10: Tela que exibe a definição do verbete "Alvéolo Pulmonar".

Em todas as etapas citadas anteriormente, os dados provenientes do servidor são formatados em um JSON. A cada requisição, tanto os glossários quanto os verbetes, os registros são paginados e retornados de 15 em 15, sendo neste caso implementada a funcionalidade de rolagem infinita, para que após rolar até o fim da página, uma requisição automática é feita ao servidor para que 
sejam enviados mais 15 registros.

\subsubsection{Módulo de Avaliação de Sinais}

É no módulo de avaliação de sinais que usuários do tipo "Membro do Comitê" podem avaliar um sinal-termo para um determinado conceito, podendo aprovar, reprovar ou propor um sinal-termo.

Um comitê avaliador pode ser formado por uma quantidade não definida de pessoas, então um sinal-termo será aprovado ou não se a maioria dos membros do comitê votarem contra ou a favor do sinal-termo. Caso o sinal-termo seja reprovado pelos membros do comitê, será solicitado um novo sinal-termo e o mesmo será reavaliado pelo comitê.

Para os usuários do tipo "Membro do Comitê" o menu da plataforma contém a opção que vai para o módulo de avaliação de sinais. Ao acessar este módulo um membro do comitê tem acesso à uma tela semelhante à da Figura 9. Como pode ser visto na Figura 11, o membro do comitê pode votar se ele aprova o termo ou não e deixar um comentário justificando a sua avaliação. Atualmente este módulo oferece ao membro do comitê somente a possibilidade de visualizar os dados da microestrutura do verbete e votar pela aprovação ou não do sinal-termo ainda não validado. Em trabalhos futuros, será permitido aos usuários do tipo "Membro do Comitê" a visualização completa da ficha lexicográfica proposta por Lima (2014).

Caso o comitê avaliador reprove um sinal-termo e queira adequá-lo, três passos deverão ser seguidos:

1. Deve ser gravado um novo vídeo para o sinal-termo proposto;

2. Deve ser feita a transcrição do sinal-termo para o SignWriting;

3. Um membro do comitê deve acessar a área administrativa da plataforma e fazer o upload dos arquivos gerados nos passos 1 e 2 .

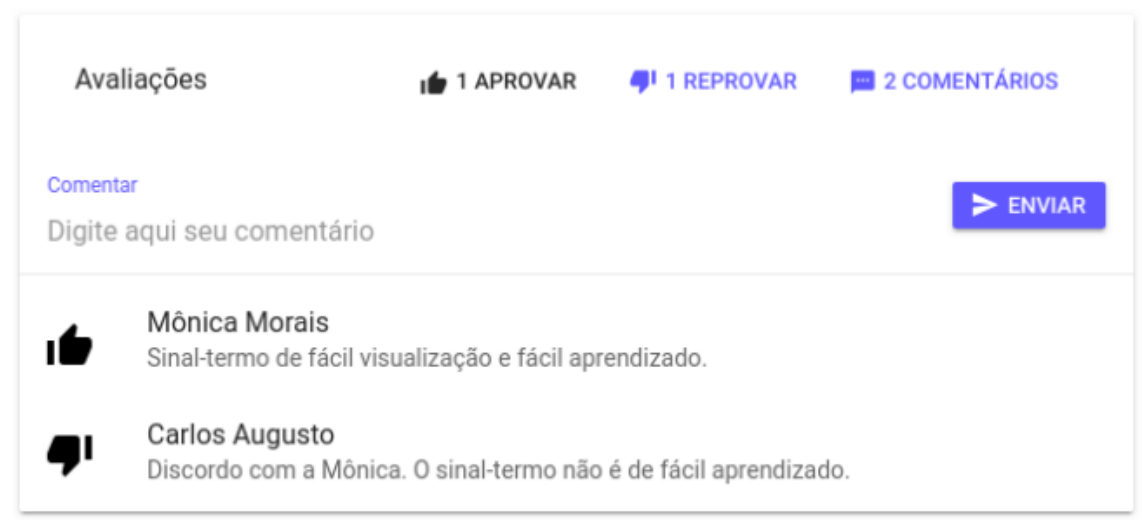

Figura 11: Área da plataforma onde um usuário do tipo "Membro do Comitê" avalia um sinal-termo. 
- Inicialmente o vídeo era armazenado no servidor ao qual a aplicação está hospedada, mas devido ao tamanho dos arquivos de vídeos e à possibilidade de reduzir a qualidade do vídeo para a realização do streaming em conexões lentas, o vídeos estão sendo armazenados no serviço Vimeo. Então, após realizar o upload do vídeo do sinal-termo, basta somente inserir, no campo correspondente ao vídeo do sinal-termo, a url do Vimeo que aponta para o vídeo.

A área administrativa está disponível no endereço http://api.signweaver.com.br/admin/ terms. Após fazer o login, o membro do comitê deve buscar pelo termo que deseja propor um novo sinal-termo e selecionar a opção de alteração, como mostrado na Figura 12 e posteriormente colocar a url do video do sinal-termo e fazer o upload do SignWriting, como pode ser visto na Figura 13.

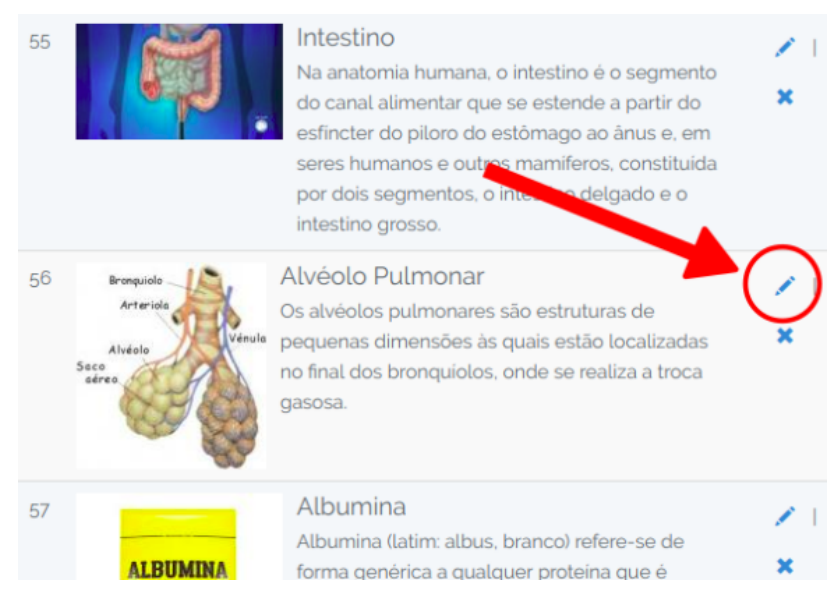

Figura 12: Selecionando a opção de alteração dos dados do verbete "Alvéolo Pulmonar".

\subsubsection{Módulo de Geração de Sinais}

Como já falado anteriormente, o gerador de sinais não será desenvolvido neste módulo. Neste módulo foi desenvolvida a interface para que o administrador possa cadastrar um verbete para o gerador de sinais e inserir o SignWriting para um determinado conceito. Esta interface permite que os administradores da plataforma possam inserir a ilustração, o termo em língua oral e a definição de cada conceito sem sinal, a Figura 14 mostra a tela que provê esta funcionalidade.

\subsubsection{Módulo de Sinalização}

É neste módulo onde os sinais propostos pelo comitê avaliador, coletados de outros trabalhos ou gerados pelo módulo 4 serão sinalizados. A partir dos SignWritings, os sinais-termo devem ser sinalizados por surdos ou intérpretes de Libras e gravados em vídeo. Após isso, devem ser adicionados à plataforma conforme mostrado na Figura 13. Como dito anteriormente, 


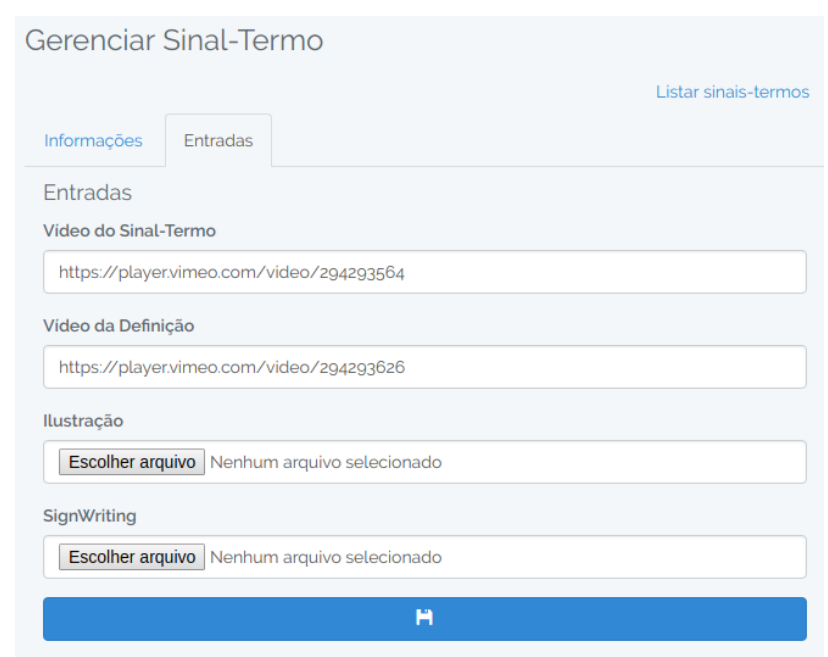

Figura 13: Alterando o video do sinal-termo e o SignWriting de "Alvéolo Pulmonar".

na Subsubseção 4.3.3, os arquivos de vídeo serão armazenados no Vimeo, bastando somente adicionar a url do vídeo.

Este módulo é necessário para que os usuários finais da plataforma possam ver a sinalização do sinais buscados.

\section{Avaliação da Plataforma}

Após o término da etapa de desenvolvimento da plataforma SignWeaver, foi realizada a avaliação da plataforma com o intuito verificar se a SignWeaver de fato possibilitou aos usuários acessarem os glossários e os sinais-termo de forma que entendessem o conceito de cada verbete. Com isso, este experimento possibilitou demonstrar que a plataforma SignWeaver tinha as características necessárias para dar suporte à criação, validação e preservação de glossários em línguas de sinais.

Como este trabalho teve o envolvimento de humanos para responder o questionário, o projeto foi submetido ao Comitê de Ética em Pesquisa (CEP) por meio da Plataforma Brasil e deferido em 19 de outubro de 2018. O número do parecer é 2.971.375 e o número do Certificado de Apresentação para Apreciação Ética (CAAE) é 98551118.8.0000.8507.

No desenvolvimento do projeto de avaliação da plataforma enviado para o CEP, foi desenhado um protocolo para realização dos experimentos. Este protocolo basicamente é composto por 4 etapas:

1. Elaboração do cenário de avaliação;

- Definição dos glossários que estariam disponíveis durante a realização dos experimentos; 


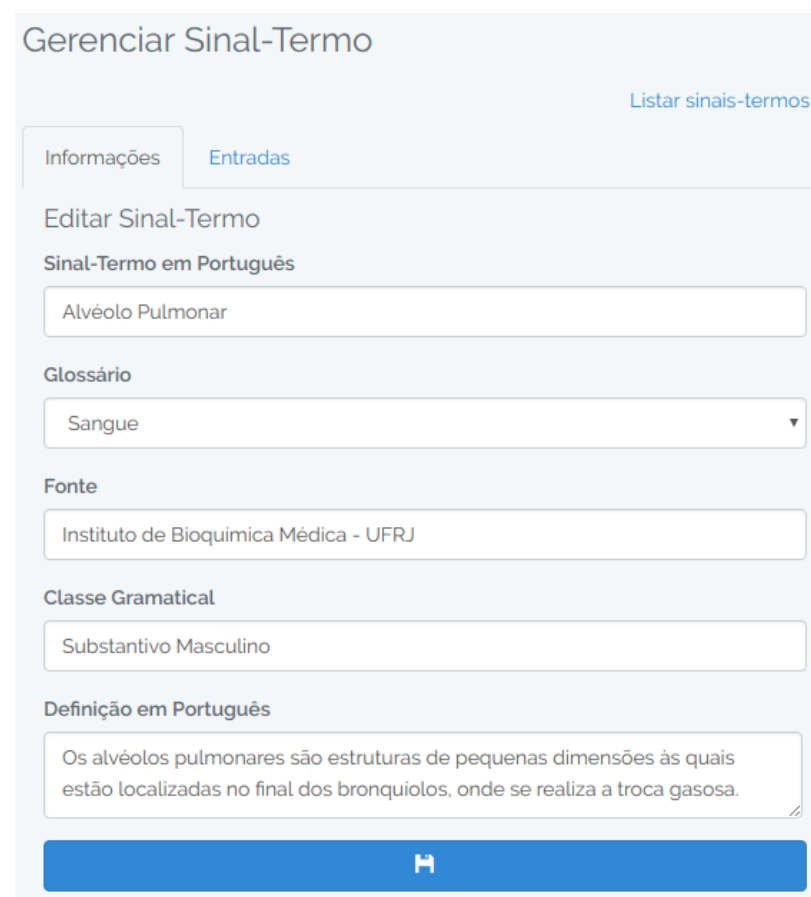

Figura 14: Tela serão inseridos os dados de um conceito para registro no sistema e geração do sinal-termo.

- Definição do público alvo;

- Definição das ações que os participantes deveriam executar;

2. Desenvolvimento do questionário a ser disponibilizado;

3. Envio do convite de participação no experimento;

4. Processamento das respostas enviadas pelos participantes.

Para um melhor entendimento, esta seção apresenta e discute de forma mais abrangente os passos necessários para a execução dos experimentos, desde a criação do cenário de avaliação até o resultado das avaliações pelos usuários.

\subsection{Cenário de Avaliação}

Para a avaliação da plataforma, após o desenvolvimento da mesma, foi necessário inserir glossários e seus respectivos verbetes. Para isso, foram utilizados vídeos com sinais-termo e explicações para conceitos das áreas de biologia e biomedicina que foram produzidos por uma equipe de graduandos, mestrandos e doutorandos da UFRJ, durante o Projeto Surdos, iniciado em 2005 e coordenado pela Profa. Vivian Rumjanek, pesquisadora da área de imunologia e oncobiologia do Instituto de Bioquímica Médica Leopoldo de Meis (IBqM) da UFRJ (Barral et 
al., 2017). Estes sinais-termo também podem ser encontrados no canal do projeto no Youtube, no seguinte endereço: https://www.youtube.com/channel/UCliRAMOOdI-S9viSrMB2obw.

Os vídeos produzidos por Barral et al. (2017) foram editados para que fosse separado o sinal-termo da explicação e posteriormente foram agrupados em 4 glossários conforme exibido na Tabela 1.

Tabela 1: Número de verbetes por glossário .

\begin{tabular}{cc}
\hline Glossário & Quantidade de Verbetes \\
\hline Célula & 43 \\
Embriogênese & 65 \\
Sangue & 84 \\
Sistema Imune & 60 \\
TOTAL & 252 \\
\hline
\end{tabular}

Foram selecionadas 65 pessoas para que pudessem responder um questionário avaliativo, sobre a plataforma, disponibilizado na internet. Os indivíduos que participaram do grupo de avaliação são compostos por 36,9\% de surdos ( 24 pessoas) e $63,1 \%$ de ouvintes (41 pessoas).

Ao participar da avaliação da plataforma, o respondente deveria seguir dois passos:

1. Cadastro e utilização da plataforma;

2. Responder o questionário disponibilizado na internet.

\subsection{Questionário de Avaliação}

Foram enviados e-mails para os participantes para que os mesmos pudessem acessar a plataforma e posteriormente responder o questionário disponibilizado na Internet por meio da ferramenta Formulários Google.

A primeira parte do questionário teve como objetivo identificar o participante. Os dados obtidos na primeira parte do questionário foram:

1. Qual a data o participante respondeu o questionário;

2. Qual o nome completo do participante;

3. Qual o documento de identificação (RG ou CPF) do participante;

4. Qual a data de nascimento do participante;

5. Qual a escolaridade do participante;

6. Qual a formação/atuação do participante; 
7. Se o participante era surdo e em caso afirmativo com qual idade ele começou a falar Libras;

8. Qual o nível de proficiência em Libras do participante.

A segunda parte do questionário foi responsável por coletar a opinião do participante do experimento acerca da plataforma. As perguntas e as possíveis respostas realizadas foram:

Pergunta 1: "Onde você utilizou a SignWeaver?";

- Possíveis respostas: "Em um celular ou tablet" ou "Em um computador".

Pergunta 2: "Quão amigável é a interface da SignWeaver?";

- Possíveis respostas: "Extremamente amigável", "Muito amigável", "Moderadamente amigável”, "Pouco amigável” ou "Nada amigável".

Pergunta 3: "Quão fácil é encontrar um sinal-termo na SignWeaver?";

- Possíveis respostas: "Extremamente fácil", "Muito fácil", "Moderadamente fácil", "Pouco fácil" ou "Nada fácil".

Pergunta 4: "Quão fácil é encontrar um glossário na SignWeaver?”;

- Possíveis respostas: "Extremamente fácil", "Muito fácil”, "Moderadamente fácil", "Pouco fácil" ou "Nada fácil".

Pergunta 5: "De forma geral, quão satisfeito ou insatisfeito está com a SignWeaver?";

- Possíveis respostas: "Extremamente satisfeito", "Pouco satisfeito", "Nem satisfeito nem insatisfeito", "Pouco insatisfeito" ou "Extremamente insatisfeito".

Pergunta 6: "Você conhece algum software (aplicativo móvel ou página web) que disponibilize glossários bilíngues (Libras-Português)?";

- Possíveis respostas: "Sim" ou "Não".

Pergunta 7: "Se você respondeu "sim"para a resposta anterior, qual software você conhece?";

- Possíveis respostas: Argumentativa.

Pergunta 8: "Quais são as suas sugestões para melhorarmos a SignWeaver?".

- Possíveis respostas: Argumentativa.

Os conjuntos de dados utilizados nos experimentos estão disponíveis gratuitamente no canal do Youtube do projeto desenvolvido por Barral et al. (2017) no endereço https://www.youtube .com/channel/UCliRAMOOdI-S9viSrMB2obw. 


\subsection{Resultados da Avaliação}

Após a realização dos experimentos, as respostas, da primeira parte do questionário, foram processadas e a partir delas foi possível identificar algumas características dos participantes:

- Como pode ser visto no gráfico mostrado na Figura 15, 64,5\% participantes afirmaram ser ouvintes e $35,5 \%$ afirmaram ser surdos.

- Como pode ser visto no gráfico mostrado na Figura 16, 41,5\% dos participantes tinham pósgraduação, $40 \%$ tinham curso superior, 6,2\% curso técnico e 12,3\% tinham ensino médio;

- Dos surdos que responderam o questionário, $75 \%$ afirmaram possuir curso superior ou pós-graduação.

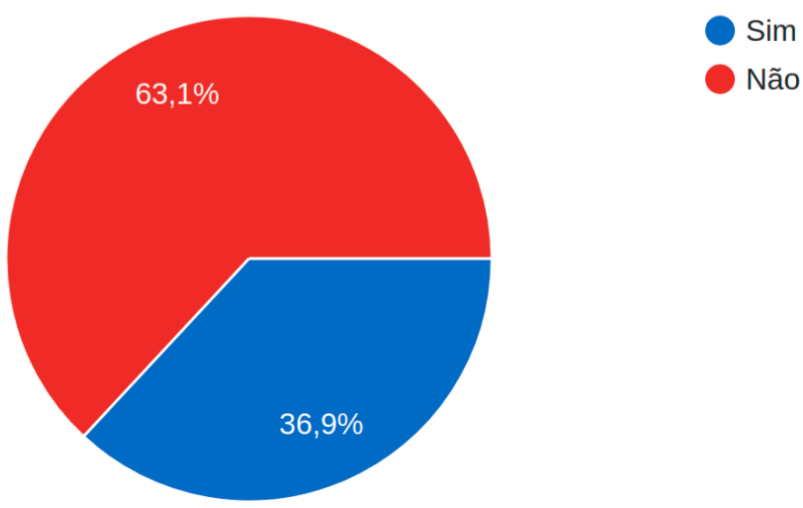

Figura 15: Gráfico que mostra a proporção de surdos que participaram do experimento

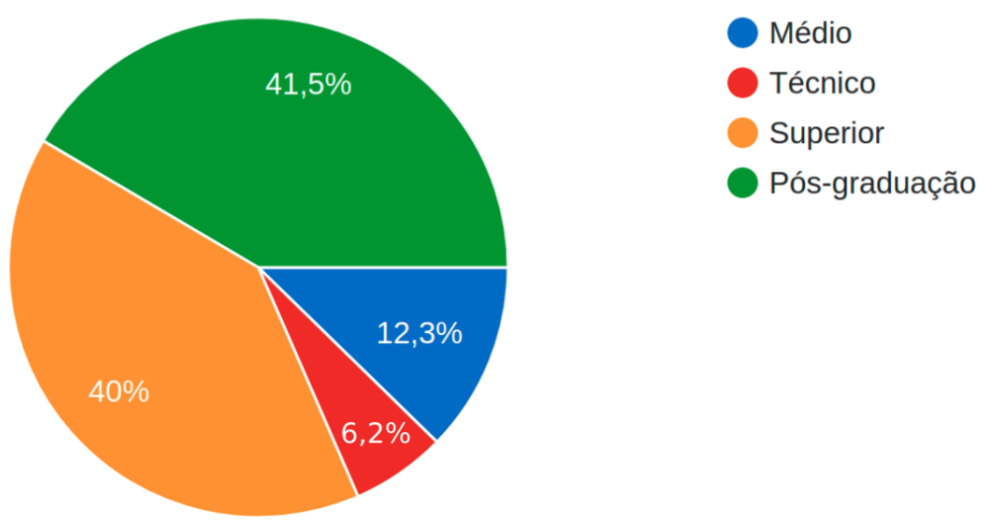

Figura 16: Gráfico que mostra a escolaridade dos participantes do experimento.

Com as respostas da segunda fase do questionário, foi possível identificar as opiniões dos participantes sobre a plataforma: 
- Como pode ser visto no gráfico mostrado na Figura 17, 69,2\% dos participantes afirmaram que a interface da plataforma é extremamente ou muito amigável;

- Aproximadamente $30 \%$ dessas pessoas já conhecem outro software que disponibiliza glossários bilíngues (Libras-Português).

- Como pode ser visto no gráfico mostrado na Figura 18, 63,1\% dos participantes acreditam ser extremamente ou muito fácil encontrar um sinal-termo na plataforma;

- Como pode ser visto no gráfico mostrado na Figura 19, 72,3\% dos participantes acreditam ser extremamente ou muito fácil encontrar um glossário na plataforma;

- Como pode ser visto no gráfico mostrado na Figura 20,60\% dos participantes acreditam estar extremamente satisfeitos em utilizar a plataforma.

- Dessas pessoas, aproximadamente $31 \%$ são surdos e $87 \%$ afirmaram possuir curso superior ou pós-graduação.

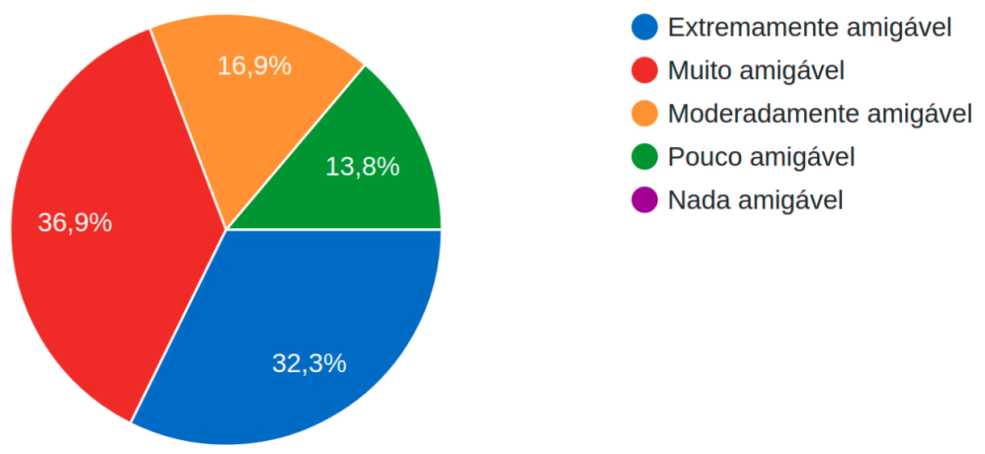

Figura 17: Gráfico que mostra o quão amigável a plataforma é para os usuários.

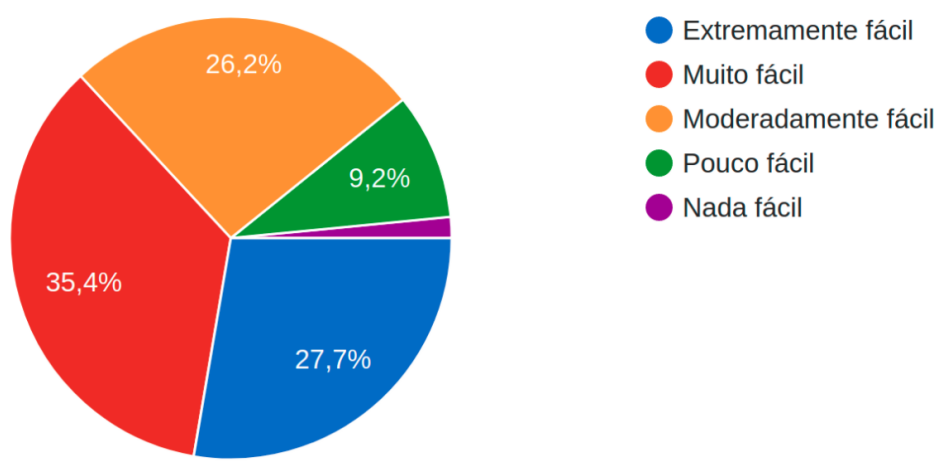

Figura 18: Gráfico que mostra o quão fácil, para os usuários, é encontrar um sinal-termo na plataforma.

Ao observar as respostas de quatro perguntas do questionário, sendo elas: 


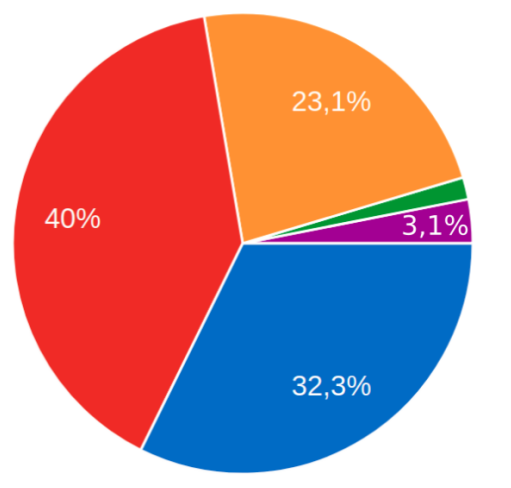

Extremamente fácil

Muito fácil

Moderadamente fácil

Pouco fácil

Nada fácil

Figura 19: Gráfico que mostra o quão fácil, para os usuários, é encontrar um glossário na plataforma.

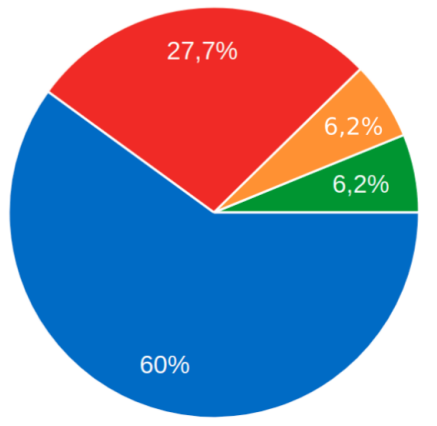

Extremamente satisfeito

Pouco satisfeito

Nem satisfeito nem insatisfeito

Pouco insatisfeito

Extremamente insatisfeito

Figura 20: Gráfico que mostra o quão satisfeitos os usuários estão em utilizar a plataforma.

Pergunta 2: “Quão amigável é a interface da SignWeaver?”;

Pergunta 3: “Quão fácil é encontrar um sinal-termo na SignWeaver?”;

Pergunta 4: "Quão fácil é encontrar um glossário na SignWeaver?”;

Pergunta 5: "De forma geral, quão satisfeito ou insatisfeito está com a SignWeaver?".

pode-se transformar as suas respostas em graus de intensidade, sendo o valor 1 a resposta mais negativa até 5 a resposta mais positiva. Sabendo disso é possível fazer uma análise geral.

Gerando um histograma para as respostas de cada pergunta (Figura 21), pode-se verificar que há uma contagem de menos de 10 pessoas, por pergunta, em um total de 65 que responderam de forma negativa.

Ao considerar o número de avaliações positivas recebidas nas questões citadas acima, notase um total de $73 \%$ de aprovação. Este cálculo pode ser encontrado somando as respostas 4 e 5 da Figura 21. As respostas 4 e 5 da Figura 21 representam as avaliações positivas, um total de 190 em 260. Esta proporção de $73 \%$ de avaliações positivas mostra que os usuários avaliaram positivamente a plataforma. 


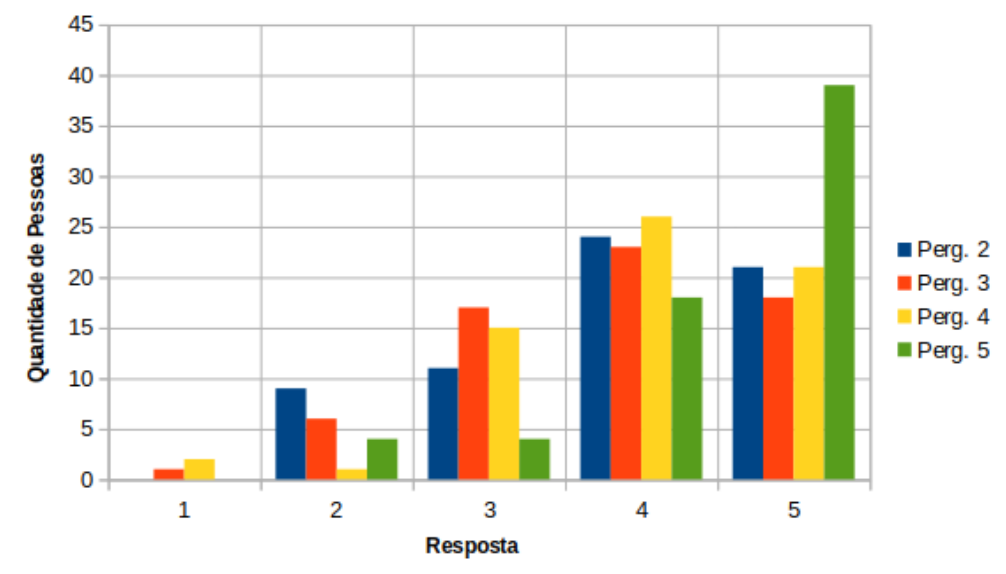

Figura 21: Histograma das perguntas 2, 3, 4 e 5.

\section{Conclusão}

Neste trabalho foi apresentado o desenvolvimento de uma plataforma digital que apoia a criação, validação, preservação e divulgação de terminologia em línguas de sinais. Apesar do acesso à terminologia em línguas de sinais ser fundamental para garantir o acesso de estudantes surdos ao ensino, não existe no país uma plataforma que disponibiliza sinais-termo, validados por linguistas, para as mais diversas áreas do conhecimento.

Como produto deste trabalho, foi desenvolvida uma plataforma computacional que pode ser utilizada em vários sistemas operacionais (Linux, Windows, Android, iOs, etc.). A possibilidade de poder ser utilizada em dispositivos móveis facilita a utilização da plataforma em sala de aula, tanto por alunos como professores e intérpretes.

Apesar de ter como resultado uma plataforma digital, este projeto é interdisciplinar e envolve as áreas de Linguística e Computação. O caráter interdisciplinar fica evidente no processo de validação dos sinais, além disto, todo o sistema foi projetado atendendo às demandas da comunidade surda e de linguistas.

A plataforma desenvolvida pode se tornar uma das principais bases de sinais-termo para a Libras, pois além de auxiliar a criação de dicionários, pode-se fazer um levantamento de dicionários já existentes e adicioná-los à base de dados do sistema. Muitos dos trabalhos propostos para a criação de dicionários não possuem linguistas em sua equipe que possam validar os dicionários criados, sendo assim, o sistema proposto pode ser um meio de validar estes dicionários.

Nos experimentos, a plataforma foi avaliada pelos usuários e $87,1 \%$ dos usuários disseram estar satisfeitos com a mesma. Este resultado mostra o potencial da SignWeaver em se tornar uma plataforma que possa ser utilizada pela comunidade.

Este trabalho contribui significativamente para o compartilhamento de conteúdo em Libras, pois os sinais-termo podem ser armazenados e disponibilizados em uma plataforma online, 
podendo ser acessados a partir de qualquer dispositivo com conexão com a Internet.

\subsection{Trabalhos Futuros}

Este trabalho cumpriu com o objetivo de auxiliar a validação, armazenamento e divulgação de sinais-termo para conceitos técnicos. Apesar de já terem sido desenvolvidas as funcionalidades que permitem cadastrar verbetes sem sinal-termo na plataforma, ainda falta integrar a plataforma com o gerador de sinais proposto por Souza, Pádua, et al. (2018), pois caso um sinal seja criado pelo gerador de sinais, o sinal-termo proposto deve ser cadastrado manualmente na plataforma. Além disso, deve-se identificar, analisar e documentar os requisitos necessários para transformação do protótipo da plataforma SignWeaver em um produto, avaliando-se as limitações atuais deste protótipo e as demandas apresentadas pelos seus potenciais usuários (surdos, intérpretes, entre outros).

Atualmente na plataforma estão cadastrados somente 7 glossários, sendo assim pode ser considerado como trabalho futuro a criação ou a disponibilização de uma quantidade de dicionários suficientemente grande para suprir a carência de sinais-termo em Libras para as mais diversas áreas do conhecimento. Além disso, pode-se almejar a criação e disponibilização de dicionários em outras línguas de sinais, como por exemplo a Língua de Sinais Americana.

Deve-se estabelecer parcerias com instituições brasileiras que criam e validam sinais-termo em Libras referentes a conceitos técnico-científicos e, mediante autorizações destas instituições, incluí-los na plataforma SignWeaver, realizando o registro em vídeo, dos sinais-termo, caso não possuam a sinalização registrada em vídeo.

Atualmente, o Laboratório de Pesquisas Interdisciplinares em Informação Multimídia do Departamento de Computação do CEFET-MG (Piim-Lab) não possui uma estrutura que permita a gravação dos vídeos dos sinais-termo. Sendo assim, deve-se estruturar um estúdio para gravações de vídeos contendo as interpretações dos sinais-termo que eventualmente forem incluídos na plataforma SignWeaver.

Os sinais-termo cadastrados na plataforma não possuem a transcrição para o SignWriting, então, como trabalho futuro, deve-se realizar a transcrição destes sinais-termo para o SignWriting .

Atualmente, não há integração com o Facebook ou o Google para facilitar o cadastro ou o login de usuários na plataforma, portanto será necessário desenvolver a integração com, pelo menos, o Facebook e o Google.

Para realizar a busca de um conceito na plataforma, o usuário deve selecionar um glossário para somente assim ter acesso à ferramenta de busca. Deve-se disponibilizar a ferramenta de busca em todas as áreas da plataforma, permitindo também buscar por glossários.

Deve-se mapear continuamente o estado da arte referente a trabalhos que explorem a produção terminológica em línguas de sinais e, quando possível, incorporar à plataforma SignWeaver eventuais ideias e métodos propostos nestes trabalhos. 


\section{Referências}

Barral, J., Da Silva, W. S., e Rumjanek, V. M. (2017). O surdo e a ciência. Em Ii congresso nacional de ensino de ciências e formação de professores-cecifop (p. 1130-1139). ([GS Search])

Bigham, J. P., Otero, D. S., DeWitt, J. N., Cavender, A., e Ladner, R. E. (2008). Asl-stem forum. Em International aaai conference on web and social media - icwsm (p. 176-177). ([GS Search])

Brasil. (2002). Lei $n^{o}$ 10.436, de 24 de abril de 2002. Brasília, DF, Brasil. Disponível em: http://www.planalto.gov.br/ccivil_03/leis/2002/L10436.htm ([GS Search])

Brasil. (2005). Decreto $n^{o}$ 5.626, de 22 de dezembro de 2005. Brasília, DF, Brasil. Disponível em: http://www.planalto.gov.br/ccivil_03/_ato2004-2006/2005/decreto/d5626.htm （[GS Search])

Capovilla, F. C., Raphael, W. D., e Mauricio, A. C. (2008). Novo deit-libras. EdUSP. ([GS Search])

Carmona, J. C. C., et al. (2015). A dicionarização de termos em língua brasileira de sinais (libras) para o ensino de biologia (Unpublished master's thesis). Universidade Tecnológica Federal do Paraná. ([GS Search])

Cavender, A., e Ladner, R. E. (2010). Ntid international symposium on technology and deaf education. ACM SIGACCESS Accessibility and Computing(97), 3-13. ([DOI:10.1145/1873532.1873533] [GS Search])

Drigas, A. S., Vrettaros, J., Stavrou, L., e Kouremenos, D. (2004). E-learning environment for deaf people in the e-commerce and new technologies sector. WSEAS Transactions on Information Science and Applications, 1(5), 1189-1196. ([GS Search])

Felipe, T. A. (2006). Os processos de formação de palavra na libras. ETD-Educação Temática Digital, 7(2), 200-217. ([GS Search])

Hockett, C. F. (1960). The origin of speech. Scientific American, 203(3), 88-97. ([GS Search])

Holgate, S. A. (2015). Strength in disability. Science, 347(6229), 1510-1510. ([DOI:10.1126/science.347.6229.1510] [GS Search])

IBGE. (2010). Censo demográfico 2010. Rio de Janeiro. Disponível em: www.ibge.gov.br/ censo2010/ ([GS Search])

Johnston, T. A. (1989). Auslan. University of Sydney Sydney. ([GS Search])

Kushalnagar, R. S., Cavender, A. C., e Pâris, J.-F. (2010). Multiple view perspectives: Improving inclusiveness and video compression in mainstream classroom recordings. Em Proceedings of the 12th international acm sigaccess conference on computers and accessibility (p. 123130). ACM. ([DOI:10.1145/1878803.1878827] [GS Search])

Lima, V. L. d. S. e. (2014). Língua de sinais (Doutorado em Linguística Teórica e Descritiva). Faculdade de Letras, Universidade Federal de Minas Gerais, Belo Horionte, MG, Brasil. ([GS Search])

Marschark, M., e Spencer, P. E. (2010). The oxford handbook of deaf studies, language, and education (1st ed., Vol. 2). Oxford University Press. ([GS Search]) 
Nakamura, K. (1995). About american sign language. Web site: http://www.deaflibrary.org/asl.html. ([GS Search])

Nascimento, M. V. B., et al. (2011). Interpretação da língua brasileira de sinais a partir do gênero jornalístico televisivo. Programa de Linguística Aplicada e Estudos da Linguagem. São Paulo: LAEL/PUC-SP. ([GS Search])

OMS. (2017). Deafness and hearing loss. Disponível em: http://www.who.int/mediacentre/ factsheets/fs300/en/

Prillwitz, S. (1989). Hamnosys: Version 2.0; hamburg notation system for sign languages; an introductory guide. Signum-Verlag. ([GS Search])

Roberson, L. (2001). Integration of computers and related technologies into deaf education teacher preparation programs. American Annals of the Deaf, 146(1), 60-66. ([GS Search])

Rocha, D. F. S., Pinto, I. I. B. S., e Silva, R. d. A. (2015). Assistlibras: An authoring tool for building signs of libras. Brazilian Journal of Computers in Education, 23(190). ([DOI:10.5753/rbie.2015.23.02.190] [GS Search])

Rocha, P. S. R., Lima, R. d., e Queiroz, P. G. (2018). Technologies for the teaching of brazilian sign language (libras) - a systematic literature review. Brazilian Journal of Computers in Education, 26(03), 42. Disponível em: http://br-ie.org/pub/index.php/rbie/article/view/7140 ([DOI:10.5753/rbie.2018.26.03.42] [GS Search])

Souza, C. L. d., de Lima, V. L. d. S. e., e Pádua, F. L. C. (2014). Abordagem interdisciplinar para a criação e preservação de novos sinais para dicionários terminológicos em libras. Acta Semiótica et Lingvistica, 19(1), 76-90. ([GS Search])

Souza, C. L. d., de Lima, V. L. d. S. e., e Pádua, F. L. C. (2018). Podem máquinas criar sinais? Espaço, 49, 35-53.

Souza, C. L. d., Pádua, F., Lima, V., Lacerda, A., e Carneiro, C. (2018). A computational approach to support the creation of terminological neologisms in sign languages. Computer Applications in Engineering Education. ([DOI:10.1002/cae.21904] [GS Search])

Stumpf, M. R. (2005). Aprendizagem de escrita de língua de sinais pelo sistema signwriting (Doutorado em Informática na Educação). Centro de Estudos Interdiciplinares em Novas Tecnologias da Educação, Universidade Federal do Rio Grande do Sul, Porto Alegre, RS, Brasil. ([GS Search])

Sutton, V. (1995). Lessons in sign writing: Textbook. Deaf Action Committee For SignWriting. ([GS Search])

Travassos Sarinho, V. (2017). Libraszap-um jogo baseado em mensagens instantâneas para avaliação de conhecimentos na língua brasileira de sinais. Revista Brasileira de Informática na Educação, 25(1). ([DOI:10.5753/rbie.2017.25.01.44] [GS Search]) 